\title{
Identification of Grown-In Defects in CZ Silicon after Cu Decoration
}

\author{
Kun-Lin Lin ${ }^{*}$, Yi-Ling Jian1, Che-Yu Lin², Chien-Cheng Lin², Yih-Rong Luo³, Chien-Chia Tseng3 \\ ${ }^{1}$ National Nano Device Laboratories, National Applied Research Laboratories, Taiwan \\ ${ }^{2}$ Department of Materials Science and Engineering, National Chiao Tung University, Taiwan \\ ${ }^{3}$ AUO Crystal Corporation, Taiwan \\ Email: *kllin@narlabs.org.tw
}

How to cite this paper: Lin, K.-L., Jian, Y.-L., Lin, C.-Y., Lin, C.-C., Luo, Y.-R. and Tseng, C.-C. (2017) Identification of Grown-In Defects in CZ Silicon after Cu Decoration. Microscopy Research, 5, 11-19. https://doi.org/10.4236/mr.2017.52002

Received: March 16, 2017

Accepted: April 15, 2017

Published: April 18, 2017

Copyright $\odot 2017$ by authors and Scientific Research Publishing Inc. This work is licensed under the Creative Commons Attribution International License (CC BY 4.0).

http://creativecommons.org/licenses/by/4.0/ (c) (i) Open Access

\begin{abstract}
Bulk Czochralski silicon crystals were decorated with $\mathrm{Cu}$ and characterized by transmission electron microscopy (TEM) with energy-dispersive spectroscopy (EDS), atomic force microscopy (AFM), optical microscopy (OM), scanning electron microscopy (SEM), and photoluminescence spectroscopy (PL). The vacancy-type core, oxidation-induced stacking faults (OISF) ring, nearly defect-free ring, and self-interstitial-type rich outer ring were delineated in the $\mathrm{Si}$ crystal wafer. At the surface of the $\mathrm{Si}$ crystal, vertical-horizontal line (V-H line) defects and windmill defects (W-defects) were formed instead of OISF. The families of growth planes and directions were expressed as $\{011\}$ and $<110>$ for the V-H line and $\{010\}$ and $<010>$ for $\mathrm{W}$-defects, respectively. In addition to $\mathrm{V}-\mathrm{H}$ line defects and $\mathrm{W}$-defects, pits or voids and Si oxide with dissolved $\mathrm{Cu}$ were found in the $\mathrm{Si}$ crystal wafer.
\end{abstract}

\section{Keywords}

CZ Silicon, Cu Decoration, Microstructures, Defects, Transmission Electron Microscopy

\section{Introduction}

Integrated circuits and electronic devices are manufactured on single-crystal silicon wafers produced from silicon crystals grown primarily by the Czochralski (CZ) technique. Single-crystal silicon wafers may contain various defects that are formed during crystal growth or during the processing of the silicon wafer. The defects in silicon crystals are typically classified into the following four types based on their shapes and dimensions [1]: 1) point defects, which include silicon self-interstitials, vacancies, interstitial impurities (such as oxygen from the $\mathrm{SiO}_{2}$ 
crucible), and substitutional impurities like dopants and carbon; 2) line defects, dislocation loops, and edge and screw dislocations; 3) planar defects such as stacking faults; and 4) bulk defects, which are agglomerations of point defects. Interstitial-type and vacancy-type defects are known to exist in CZ silicon crystals, and their distributions are determined by the relation between the crystal growth rate $(v)$ and the temperature gradient $(G)$. The value of $v / G$ determines whether an interstitial-type, vacancy-type, or mixed-type silicon crystal is grown. The critical $v / G$ value $\left(\xi_{t}\right)$ is close to $1.34 \times 10^{-3} \mathrm{~cm}^{2} \cdot \mathrm{K}^{-1} \cdot \mathrm{min}^{-1}[2]$. When $v / G<\xi_{\text {o }}$ I-defects (interstitial-type defects) are dominant compared with V-defects (vacancy-type defects). In contrast, $\mathrm{V}$-defects dominate when $v / G>\xi$. Mixed-type defects (both I-defects and V-defects) are also found in silicon crystals at specific values of $v / G[3]$ [4].

In general, defects caused by interstitial elements (oxygen from the silica crucible, carbon from the graphite susceptor, dopants, and others) dissolve in the silicon crystal and are too small to be observed easily and directly by the analysis techniques such as OM, SEM, and even TEM. The rapid oxidation of the silicon wafer can enhance defect growth, allowing them to be observed after etching with select solutions such as Wright, Sirtl, Schimmel, Yang, Secco, MEMC, and Dashn (ASTM standard F 1809-02, 2003) [5]. Different types of rapid oxidation such as wet oxidation [1] [6], dry oxidation [7], and $\mathrm{Cu}$ decoration [8] [9] [10] [11] have been discussed and used to identify oxygen precipitates, dislocation loops, pits, and oxygen-induced stacking faults (OISF) in silicon crystals. $\mathrm{Cu}$ decoration is a reliable treatment for delineating the most common defect types in silicon crystals, including I-type and V-type defects and OISF regions, by the naked eye or under bright light or OM [8] [9]. In this study, $\mathrm{Cu}$ decoration technique is used to delineate pits, I-type and V-type defects, V-I boundaries, defect-free regions, and line defects. After $\mathrm{Cu}$ decoration, the defects have a specific growth direction. Thus, the purpose of the study is to elucidate the growth mechanisms of the defects in silicon crystals using $\mathrm{Cu}$ decoration combined with OM, TEM with EDS, and AFM.

\section{Experimental Procedures}

CZ silicon crystals were grown along the $<100>$ direction using conventional CZ processing. Si crystals were processed into polished 8 -inch wafers. The wafers were then subjected to the following standard $\mathrm{Cu}$ decoration treatment by Mule'Stagno [8]. A high concentration of copper nitrate $\left(\mathrm{Cu}\left(\mathrm{NO}_{3}\right)_{4} \cdot 5 \mathrm{H}_{2} \mathrm{O}\right)$ solution was spread on the back side of the wafer and heated at $50^{\circ} \mathrm{C}$ to $60^{\circ} \mathrm{C}$ on a hot plate to dry the solution. After drying, a film of copper nitrate was formed on the back of the wafer and annealed at $900^{\circ} \mathrm{C}$ for $20 \mathrm{~min}$ in a muffle furnace and air-quenched to the room. The wafer was then etched by acid etchant mixture (57\% nitric acid (70\%), 18\% hydrofluoric acid (49\%), and 25\% hydrochloric acid) and Secco Etch ( $0.15 \mathrm{M}$ potassium dichromate and $49 \%$ hydrofluoric acid, 1:2 ratio). After rinsing in deionized (DI) water and drying, the silicon wafers 
were ready for inspection. The microstructures of the silicon wafers were extensively investigated using OM, AFM (Model D5000, New York, USA), SEM (JOEL JSM 6500-F, JEOL Ltd., Tokyo, Japan), and TEM (Model JEM 2010Fx, JEOL Ltd., Tokyo, Japan) with EDS (silicon drift detector; Oxford X-Max 80). To evaluate the silicon lattice parameters, the TEM image magnification was calibrated using a $\mathrm{MAG}^{\star} \mathrm{I}^{\star} \mathrm{CAL}$ reference standard sample (Norrox Scientific, Ltd., Canada). Plane-view TEM specimens of the silicon wafers in the I-type and $\mathrm{V}$-type regions were prepared by conventional mechanical polishing and precision ion milling (Model 691, Gatan Inc., Pleasanton, CA).

\section{Results and Discussion}

Figure 1(a) shows a photograph of a radial cross section of a CZ Si crystal on the top of an ingot after $\mathrm{Cu}$ decoration under bright light. The image delineates the vacancy-type core, OISF ring, nearly defect-free ring, and self-interstitial-type rich outer ring. These defects were easily and quickly observed after $\mathrm{Cu}$ decoration, which is consistent with the report by Mule'Stagno [8]. The photoluminescence (PL) image in Figure 1(b) also delineates the boundary between V-and Idefects and the regions of the defects shown in Figure 1(a), particularly the OISF ring pattern. Figures 2(a)-(d) show OM images of the vacancy-type core, OISF ring, defect-free ring, and interstitial-type ring, respectively. Three types of defects, V-H line defects, W-defects, and pits, appear in the vacancy-type, OISF, and interstitial-type regions, but their size distributions are different. The size distributions of these defects in the vacancy-type, OISF, defect-free, and interstitial-type regions are summarized in Table 1 . The defect size is the largest in the vacancy-type region and the smallest in the OISF region. Only pits are found in the defect-free region. The size and distribution of defects in these regions can be attributed to differences in the pulling rate and temperature gradient during CZ processing [2] [3] [4]. The OISF region is composed of extrinsic (interstitial-type) faulted loops lying on the (111) plane with Frank-type partial dislocations $(\boldsymbol{b}=a / 3<111>)$ [2] [12]. The sizes of stacking faults are normally approximately 0.5 to $5 \mu \mathrm{m}$ during oxidation processing [12] [13]; however, the sizes of

Top of the ingot wafter

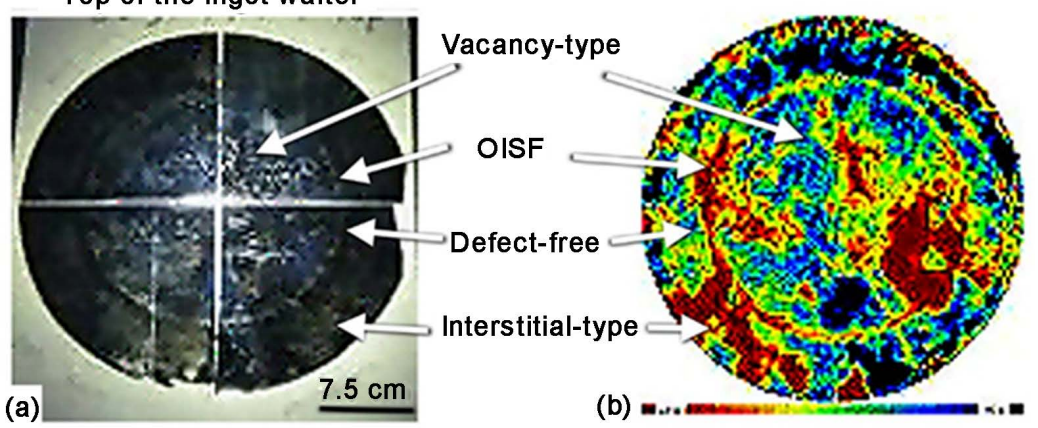

Figure 1. Photography (a) and photoluminescence PL intensity image (b) of a radial cross-section of a CZ crystal showing the vacancy-type core, the OISF ring, the nearly defect-free ring, and the self-interstitial-type rich outer ring. 


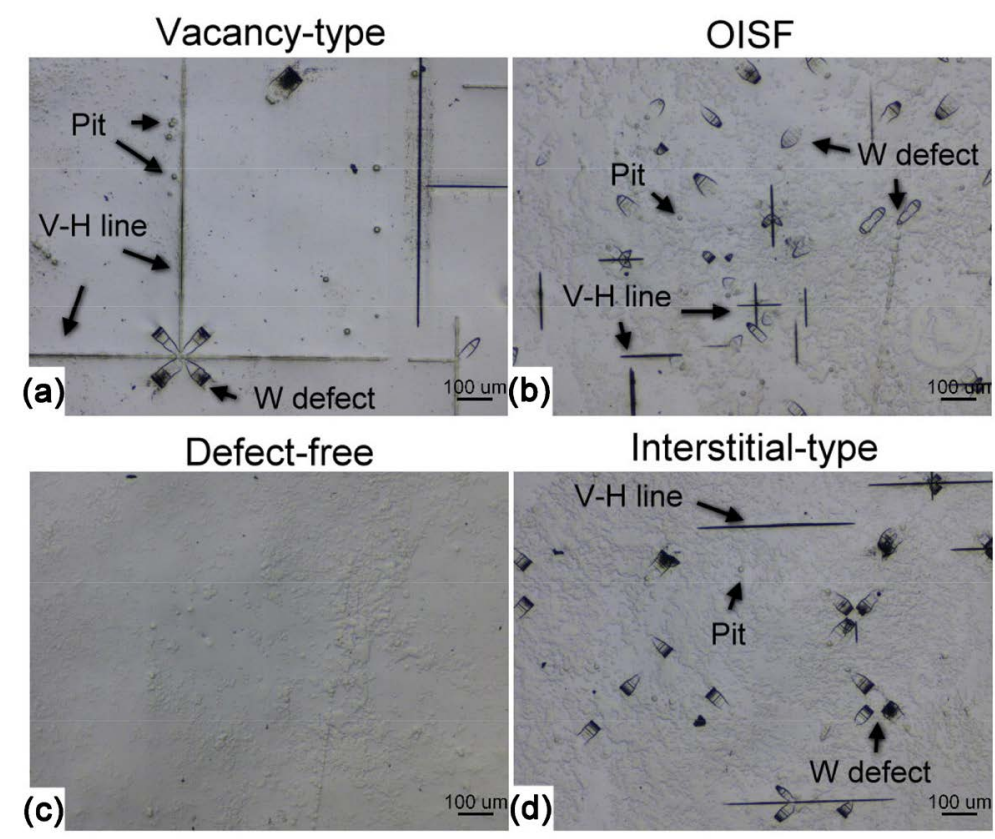

Figure 2. Optical micrographs of the vacancy-type core (a), OISF ring (b), defect-free ring (c), and interstitial-type ring (d) showing the pits, the $\mathrm{V}-\mathrm{H}$ line, and $\mathrm{W}$-defects (windmill defects).

Table 1. The sizes of pits, $\mathrm{V}-\mathrm{H}$ line, and $\mathrm{W}$-defect in the vacancy-type, OISF, defect-free, and interstitial-type regions.

\begin{tabular}{cccc}
\hline Region & Pits $(\mu \mathrm{m})$ & V-H line $(\mu \mathrm{m})$ & W defect $(\mu \mathrm{m})$ \\
\hline Vacancy-type & $16.5 \pm 1.9$ & $632.2 \pm 62.0$ & $88.7 \pm 16.2$ \\
OISF & $11.0 \pm 1.4$ & $149.7 \pm 42.4$ & $60.1 \pm 11.9$ \\
Defect-free & $13.6 \pm 1.3$ & - & - \\
Interstitial-type & $13.9 \pm 2.1$ & $374.5 \pm 61.5$ & $68.5 \pm 13.1$ \\
\hline “”
\end{tabular}

these defects in the OISF region in this study are very large (e.g., $149.7 \pm 42.4 \mu \mathrm{m}$ for a V-H line defect and $60.1 \pm 11.9 \mu \mathrm{m}$ for a W-defect; Figure 1(b) and Table $1)$.

Figure 3(a) shows a plane-view TEM image of the V-H line, displaying the $\mathrm{V}-\mathrm{H}$ line along the $[0 \overline{1} 1]$ direction. From the EDS line scanning of Figure $3(\mathrm{~b})$, the $\mathrm{V}-\mathrm{H}$ line is composed of $\mathrm{Si}$ and $\mathrm{O}$ elements. Figure 3(c) and Figure 3(d) show a high-resolution TEM (HRTEM) image and the corresponding Fourier transform diffraction pattern of the V-H line in a Si substrate along the [100] zone axis, respectively. From the EDS results, the V-H line is a Si oxide not a general OISF of previous research [12]. Besides, the growth plane or direction of $\mathrm{V}-\mathrm{H}$ line defect is along with (011) plane or [0 $\overline{1} 1]$ direction. Thus, it can be concluded that trace amounts of oxygen will induce stacking faults in the Si substrate, whereas serious oxidation processes such as $\mathrm{Cu}$ decoration could cause the formation with growth of silicon oxide in a specific direction. Figure 4(a) 


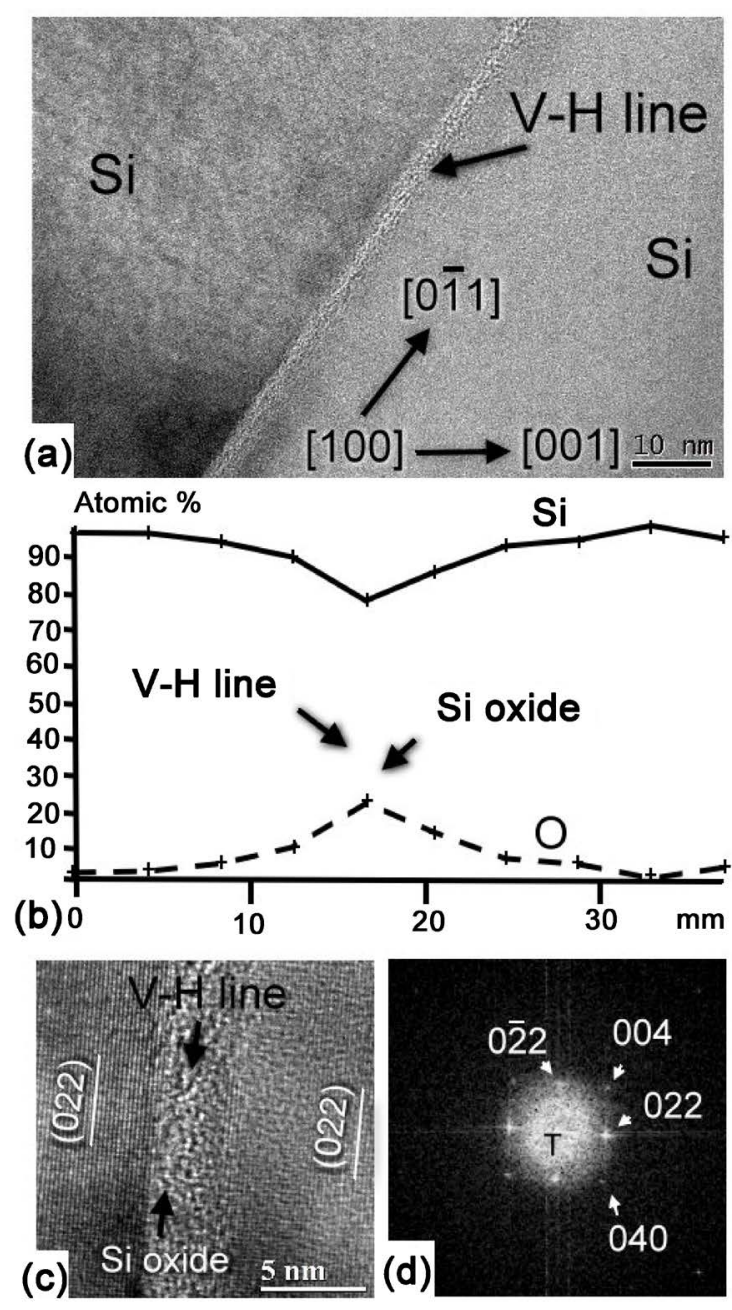

Figure 3. (a) Plane-view TEM image of the V-H line defect; (b) the composition of EDS line scanning across the $\mathrm{V}-\mathrm{H}$ line showing the existence of Si oxide; (c) HRTEM image of the $\mathrm{V}-\mathrm{H}$ line defect in an Si substrate (zone axis $=[100]$ ); and $(\mathrm{d})$ the corresponding Fourier transform diffraction pattern.

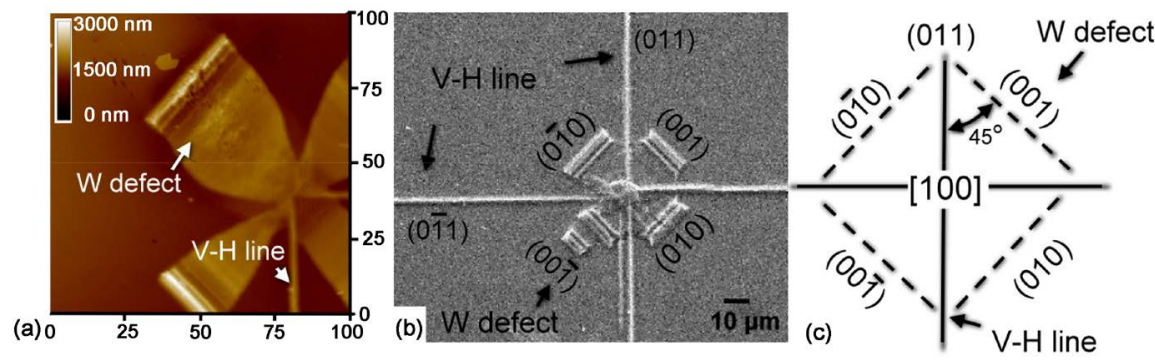

Figure 4. (a), (b) AFM and SEM images of the $\mathrm{W}$ defect and V-H line; and (c) plane indexing of the $\mathrm{W}$-defect and $\mathrm{V}-\mathrm{H}$ line.

shows an AFM image of the $\mathrm{W}$-defect and $\mathrm{V}$ - $\mathrm{H}$ line. This image indicates higher roughness (bright contrast) in these defects at the surface of the Si substrate compared with those in other regions (dark contrast). After $\mathrm{Cu}$ decoration, the 
reaction between silicon and oxygen was serious, forming $\mathrm{W}$-defect and V-H line with specific growth planes and directions. Based on the TEM and SEM images shown in Figure 4, the growth planes for W-defects are (010), $(0 \overline{1} 0),(001)$, and $(00 \overline{1})$, and those of the V-H line are $(011)$ and $(0 \overline{1} 1)$. Finally, the families of growth planes and directions for the V-H line and $\mathrm{W}$-defect should be expressed as $\{011\}$ and $\langle 110\rangle$ and $\{010\}$ and $\langle 010\rangle$, respectively.

Excepting two types of $\mathrm{W}$-defect and $\mathrm{V}-\mathrm{H}$ line in the Si crystal, another type of defect, the pits (or voids), is also found shown in Figure 2. The pits have been identified by TEM analysis as dislocation clusters that consist of dislocations and stacking faults, and the sizes of the pits after etching were reported as several tens of micrometers in a previous study [14]. In this study, the pit size is approximately 10 to $20 \mu \mathrm{m}$, consistence with the previous report [14]. However the pits are not dislocation clusters in this study, as demonstrated by TEM analysis. Figure 5 shows a plane-view TEM image of the pits and V-H line defect, indicating that the pits are voids, not dislocation clusters. The pits show bright contrast in TEM image due to the greater transmittance of the electron beam in the thin void region. Figure 5(b) shows a dark-field TEM image of Figure 5(a), displaying the strain field around the pits. The EDS spectrum [Figure 5(c)] indicates that more oxygen was detected in the pits comparing in the substrate [Figure 5(d)]. The agglomeration of vacancies in oxygen-rich silicon crystals will enhance the nucleation of oxide particles, and some oxide particles will be transformed into voids by cavitation [15]. Voronkov reported that oxide particles without accompanying vacancies cannot be formed due to the large volume mismatch between $\mathrm{Si}$ and $\mathrm{SiO}_{2}$, which produces high strain energy [16]. Both oxygen and vacancies are consumed, thus reducing the nucleation barrier of voids. Therefore, the initial oxide particles will be converted into regular voids, and a small portion of residual oxide will remain. Moreover, during the formation
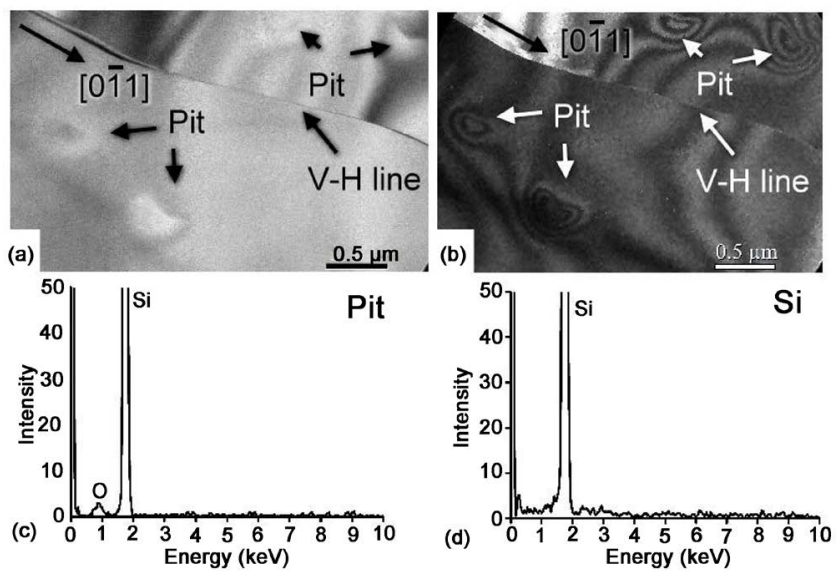

Figure 5. (a) Plane-view TEM image of the pits and V-H line defect; (b) dark-field TEM image of the sample shown in Figure 4(a) showing the strain around the pit; (c) and (d) the compositions of the pit and the Si substrate, respectively. 


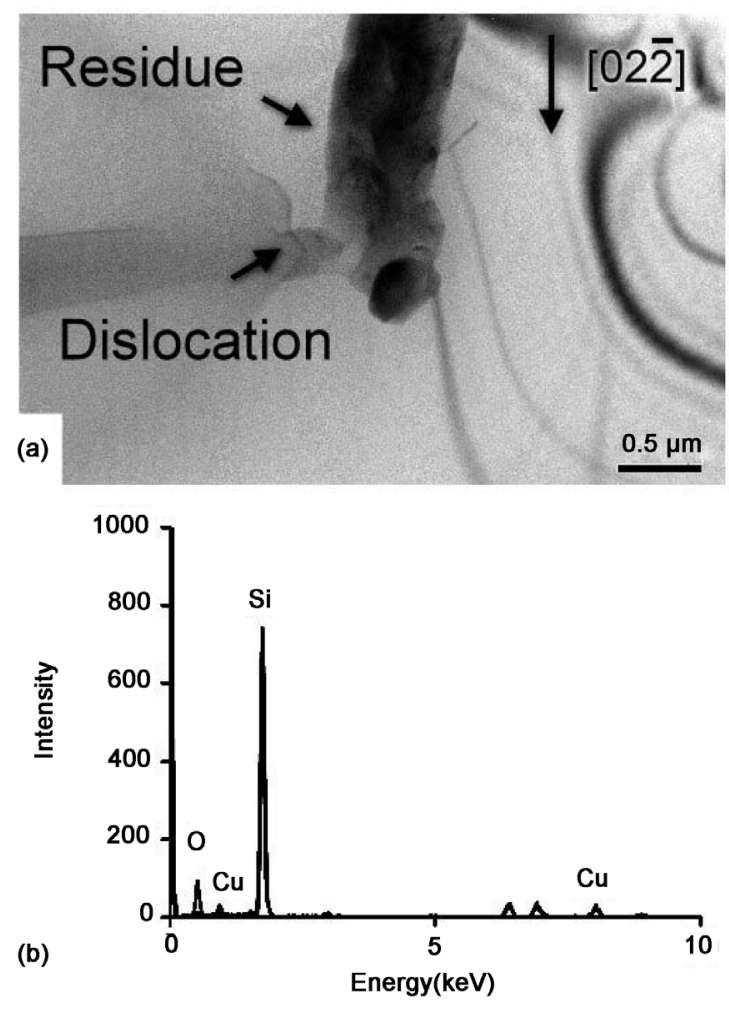

Figure 6. (a) Plane-view TEM image of the residue after $\mathrm{Cu}$ decoration and (b) composition of the residue.

of voids, a thin oxygen layer (approximately $2 \mathrm{~nm}$ in thickness) remains at the surface, as indicated by Auger [17] and TEM-EDS [18] analyses. Similarly, it is possible that a thin oxide layer formed at the surface of the void in this study, which is supported by the TEM-EDS result shown in Figure 5(c). In general, $\mathrm{Cu}$ decoration effectively enhances the growth of defects in Si crystals, allowing the defects to be easily observed by the naked eye or OM. However, some residual oxides containing $\mathrm{Cu}$ are found at the surface of the $\mathrm{Si}$ crystal wafer after $\mathrm{Cu}$ decoration. Figure 6(a) shows the plane-view TEM image of the residue after $\mathrm{Cu}$ decoration; the dislocation surrounding the residue can be observed due to the large lattice mismatch between the oxide and $\mathrm{Si}$ wafer. The residue is Si oxide containing minor $\mathrm{Cu}$ element, as indicated by the EDS spectrum in Figure 6(b). As mentioned previously, the formation of voids results from the reaction between vacancies and the Si oxide. However, some residual Si oxide could dissolve minor amounts of $\mathrm{Cu}$ in the $\mathrm{Si}$ crystal wafer using $\mathrm{Cu}$ decoration.

\section{Conclusion}

Bulk CZ silicon crystals were decorated with $\mathrm{Cu}$ and characterized by TEM-EDS, AFM, and SEM to delineate the vacancy-type core, OISF ring, nearly defect-free ring, and self-interstitial-type rich outer ring in the Si crystals wafer. Pits, Si oxides, V-H line, and W-defects were formed in the vacancy-type, OISF, defect-free, and interstitial-type regions. In the silicon crystal, V-H line defects and 
$\mathrm{W}$-defects are found instead of OISFs. The families of growth planes and directions of the $\mathrm{V}-\mathrm{H}$ line and $\mathrm{W}$-defects are expressed as $\{011\} /<110\rangle$ and $\{010\} /<010\rangle$, respectively. In addition to $\mathrm{V}-\mathrm{H}$ line and $\mathrm{W}$-defects, pits (voids) and $\mathrm{Si}$ oxides with minor amounts of dissolved $\mathrm{Cu}$ are found in the $\mathrm{Si}$ crystal during $\mathrm{Cu}$ decoration treatment.

\section{Acknowledgements}

The authors would like to thank Ms. Lidia Huang for preparing the TEM samples.

\section{References}

[1] Válek, L. and Sik, J. (2012) Defect Engineering during Czochralski Crystal Growth and Silicon Wafer Manufacturing. In: Kolesnikov, N., Ed., Modern Aspects of Bulk Crystal and Thin Film Preparation, InTech, Rijeka.

[2] Brown, R.A., Wang, Z. and Mori, T. (2001) Engineering Analysis of Microdefect Formation during Silicon Crystal Growth. Journal of Crystal Growth, 225, 97-109. https://doi.org/10.1016/S0022-0248(01)00825-9

[3] Ammon, W.V., Dornberger, E. and Hansson, P.O. (1999) Bulk Properties of Very Large Diameter Silicon Single Crystals. Journal of Crystal Growth, 198-199, 390-398. https://doi.org/10.1016/S0022-0248(98)01140-3

[4] Voronkov, V.V. (2008) Grown-In Defects in Silicon Produced by Agglomeration of Vacancies and Self-Interstitials. Journal of Crystal Growth, 310, 1307-1314. https://doi.org/10.1016/j.jcrysgro.2007.11.100

[5] ASTM standard F 1809-02 (2003) Standard Guide for Selection and Use of Etching Solutions to Delineate Structural Defects in Silicon. ASTM International, West Conshohocken.

[6] Singh, S., Debucquoy, M., Wostyn, K., Cornagliotti, E., O'Sullivan, B., Posthuma, N. and Poortmans, J. (2013) N-Type Silicon Wafer Screening for IBC Solar Cells by Different Thermal Treatments. Proceedings 28th European Photovoltaic Solar Energy Conference and Exhibition, Paris, 2 October 2013, 891-894.

[7] Romano-Rodríguez, A., Bachrouri, A, López, M., Morante, J.R., Misiuk, A., Surma, B. and Jun, J. (2000) TEM Characterization of High Pressure-High-Temperature-Treated Czochralski Silicon Samples. Materials Science and Engineering: B, 73, 250-254. https://doi.org/10.1016/S0921-5107(99)00473-0

[8] Mule'Stagno, L. (2002) A Technique for Delineating Defects in Silicon. Solid State Phenomena, 82-84, 753. https://doi.org/10.4028/www.scientific.net/SSP.82-84.753

[9] Válek, L., Stehlík, Š., Orava, J., Ďurík, M., Šik, J. and Wágner, T. (2007) Limits of the Copper Decoration Technique for Delineating of the V-I Boundary. Journal of Physics and Chemistry of Solids, 68, 1157. https://doi.org/10.1016/j.jpcs.2007.01.038

[10] Shin, J.S. and Lyo, I.W. (2003) Influence of Cu-Decoration to Individual Crystal Originated Pits on Si Wafer. Japanese Journal of Applied Physics, 42, 4187. https://doi.org/10.1143/JJAP.42.4187

[11] Wen, C.-Y. and Spaepen, F. (2007) Filling the Voids in Silicon Single Crystals by Precipitation of $\mathrm{Cu}_{3}$ Si. Philosophical Magazine, 87, 5565-5579. https://doi.org/10.1080/14786430701675811

[12] Hasebe, M., Takeoka, Y., Shinoyama, S. and Naito, S. (1989) Formation Process of Stacking Faults with Ringlike Distribution in CZ-Si Wafers. Japanese Journal of 
Applied Physics, 28, L1999. https://doi.org/10.1143/JJAP.28.L1999

[13] Xu, J., Wang, W., Yang, D. and Moeller, H.J. (2009) Transmission Electron Microscopy Investigation of the Micro-Defects in Czochralski Silicon. Journal of Alloys and Compounds, 478, 758-762.

[14] Furukawa, J., Tanaka, H., Nakada, Y., Ono, N. and Shiraki, H. (2000) Investigation on Grown-In Defects in CZ-Si Crystal under Slow Pulling Rate. Journal of Crystal Growth, 210, 26-30.

[15] Voronkov, V.V. (2000) Formation of Voids and Oxide Particles in Silicon Crystals. Materials Science and Engineering: B, 73, 69-76.

[16] Voronkov, V.V. (2008) Grown-In Defects in Silicon Produced by Agglomeration of Vacancies and Self-Interstitials. Journal of Crystal Growth, 310, 1307-1314.

[17] Ueki, T., Itsumi, M. and Takeda, T. (1997) Octahedral Void Structure Observed in Grown-In Defects in the Bulk of Standard Czochralski-Si for MOS LSIs. Japanese Journal of Applied Physics, 36, 1781-1785. https://doi.org/10.1143/JJAP.36.1781

[18] Kato, M., Yoshida, T., Ikeda, Y. and Kitagawara, Y. (1996) Transmission Electron Microscope Observation of "IR Scattering Defects" in As-Grown Czochralski Si Crystals. Japanese Journal of Applied Physics, 35, 5597-5601.

https://doi.org/10.1143/JUAP.35.5597

\section{Scientific Research Publishing}

\section{Submit or recommend next manuscript to SCIRP and we will provide best} service for you:

Accepting pre-submission inquiries through Email, Facebook, LinkedIn, Twitter, etc. A wide selection of journals (inclusive of 9 subjects, more than 200 journals) Providing 24-hour high-quality service User-friendly online submission system Fair and swift peer-review system Efficient typesetting and proofreading procedure Display of the result of downloads and visits, as well as the number of cited articles Maximum dissemination of your research work

Submit your manuscript at: http://papersubmission.scirp.org/ Or contact mr@scirp.org 